\title{
PRÁTICAS DE MEDIAÇÃO CULTURAL NAS BIBLIOTECAS PÚBLICAS MUNICIPAIS DE LONDRINA/PR
}

\author{
Bárbara Damiane da Silva \\ Mestranda em Ciência da Informação - PPGCI-UEL \\ babidamiane@gmail.com \\ João Arlindo dos Santos Neto \\ Doutorando em Ciência da Informação - UNESP \\ Professor do Departamento de Ciência da Informação - UEL \\ santosneto@uel.br
}

Resumo

\begin{abstract}
Discute sobre a mediação cultural em bibliotecas públicas e suas práticas culturais, em especial a ação cultural, fabricação cultural e animação cultural. Aborda a temática cultura em seu sentido lato e apresenta algumas formas de diluição cultural. $\mathrm{O}$ objetivo geral foi analisar as concepções dos profissionais quanto às práticas culturais. Quanto aos objetivos específicos, buscou-se identificar a realização dessas práticas, verificar se os profissionais se consideram agentes culturais e categorizar quais são as mediações realizadas por eles. Constitui uma pesquisa exploratória de natureza qualitativa, a partir de um levantamento de literatura de uma pesquisa de campo. O universo da pesquisa é o Sistema de Bibliotecas Públicas Municipais de Londrina, Paraná; a população alvo foi composta pelos profissionais deste Sistema e a técnica de coleta de dados se deu através do questionário. Os dados foram analisados a partir de categorias e confrontados com autores revisitados na fundamentação teórica. Os resultados demonstram que o Sistema desenvolve ações de mediação cultural através de diferentes práticas, como: exposições, hora do conto, oficinas etc., sendo elas, distribuídas conforme a demanda social e disponibilidade dos agentes culturais. Conclui que a concepção dos profissionais quanto às práticas culturais, condiz com o discurso da literatura utilizada no artigo, mas eles apresentam um entendimento superficial quanto ao significado delas.
\end{abstract}

Palavras-chave: Mediação cultural. Ação cultural. Fabricação cultural. Animação cultural. Sistema de Bibliotecas Públicas Municipais de Londrina.

\section{INTRODUÇÃO}

$\mathrm{O}$ artigo apresenta os resultados de um trabalho de conclusão de curso de Biblioteconomia realizado entre 2015 e 2016 que buscou investigar a mediação cultural e as práticas culturais que são desenvolvidas pelas bibliotecas públicas municipais de Londrina/PR. O problema da pesquisa foi investigar como os bibliotecários do Sistema de Bibliotecas Públicas Municipais de Londrina (SBPML) conceituam as práticas culturais que são realizadas e descobrir de que forma elas influenciam a comunidade. A problemática que levou a esta questão, devese ao fato de que na Cidade, muitos são os espaços informacionais e culturais, porém, muitos deles carecem de investimento e, também, de valorização social. Sendo assim, acredita-se que ao responder a questão proposta, poder-se-á colaborar com futuras práticas culturais a serem realizadas pelo Sistema analisado.

A partir de levantamento bibliográfico é possível afirmar que a temática - prática cultural - é pouco discutida na atualidade no domínio da Ciência da Informação (CI), tendo 
sido mais expressiva em meados dos anos 80 e, com o passar dos anos, menos.

Outra situação enfrentada pelas bibliotecas públicas refere-se aos índices de leitura e uso, que demonstram uma baixa procura por elas. Essa evasão dos usuários das bibliotecas está influenciando de forma direta as unidades e os profissionais atuantes neste campo de trabalho. Para amenizar e, até mesmo, evitar a baixa nesse índice, faz-se necessário atrair cada vez mais o usuário e a comunidade para as bibliotecas. Alguns autores como Paulo Freire (1981), Teixeira Coelho (1986, 1989, 1999) e Luís Milanesi (2003), entre outros, defendem a prática da ação cultural como possibilidade de aproximar os usuários dos equipamentos informacionais. Essa prática pode utilizar diferentes linguagens para atrair a comunidade para a biblioteca e durante essa atividade o bibliotecário ou agente cultural, exercem diferentes funções, que são discutidas ao longo desse artigo.

No decorrer do presente texto, discutiu-se a cultura, mediação cultural e as três práticas culturais mais recorrentes na literatura da área: ação, animação e fabricação cultural. O tema cultura foi apresentado brevemente com o intuito de contextualizar e introduzir os conceitos básicos e fundamentais para compreender a mediação cultural e as práticas culturais.

\section{PARA ENTENDER A CULTURA}

Os primeiros estudos a respeito do termo cultura surgiram nos séculos XVIII e XIX, com os alemães e franceses, quando o termo era empregado com o objetivo de explicar um assunto relacionado a outro, como por exemplo: culturas das letras, culturas das artes etc. No pensamento francês iluminista e universalista a cultura estava relacionada ao estado de espírito, mas para os franceses o termo cultura também se relacionava a educação e a razão. Para os alemães, a significação de cultura apresentava similaridade com o conceito francês, sendo que o conceito de cultura como civilização era utilizado pelos príncipes da aristocracia alemã (CANEDO, 2009).

Para Santos (2006), cultura é tudo aquilo que faz referência a humanidade como um todo. Além disso, ainda existem as especificações de cultura que se referem há um grupo de pessoas, uma nação, uma classe social, entre outras. $\mathrm{O}$ mencionado autor apresenta duas concepções de cultura: a primeira se reporta a todas as expressões e características de uma realidade social e/ou manifestações sociais; a segunda, se refere ao conhecimento, ideias, crenças e a forma como elas interagem na vida social.

Segundo Coelho (1989, p. 21) cultura “[...] é o que move o indivíduo, o grupo, para longe da indiferença, da indistinção, é uma construção que só pode proceder pela diferenciação. Seu oposto é diluição.” A "diluição" apresentada pelo referido autor, consiste em algo que o mercado midiático oferece à população, que seria a propagação do igual. Coelho (1989) ainda se refere a Kraus (1929) ao afirmar que quem tem a arte em si não precisa de exposição, desta forma os autores apontam que a publicidade e a exposição da arte constituem-se como consumismo e não cultura.

Cultura, portanto, se vista em seu sentido lato, pode ser compreendida como um conjunto de elementos que são incorporados pelo homem que vive em sociedade e, também aqueles, que são construídos a partir se sua inteligência, envolvendo seus gostos e comportamentos, posições e discursos, características e divergências, contextos e meio social.

Após discutir de movo breve o termo cultura e apresentar as formas de diluição cultural, é apresentado na seção seguinte o uso da cultura dentro de uma das categorias de mediação, isto é, a mediação cultural. Neste artigo, se reconhece as práticas culturais como formas de mediação cultural, visto que possuem aspectos relacionados, como pode ser visto a seguir.

\section{MEDIAÇÃO CULTURAL E SUAS PRÁTICAS}

A mediação cultural visa apresentar e tornar conhecida as diferentes manifestações culturais presentes na esfera social. Sua ação consiste em criar uma interface entre esses dois universos distintos um ao outro, arte e público, e o seu objetivo é aproximar esses dois universos (COELHO, 1999; DAVALLON, 2007). Neste caso a mediação 
tem como objetivo apresentar um elemento (seja este um objeto, uma linguagem, uma imagem), desconhecido ou pouco conhecido, a um sujeito ou grupo social com a expectativa de que haja apropriação daqueles por estes (SANTOS NETO, 2014).

Crippa e Almeida (2011) inferem que o sentido do senso comum da mediação, está ligado intrinsicamente a Ciências Sociais nas denominadas "teorias da ação", desta forma a mediação cultural possibilita a conexão entre as ações sociais e as motivacionais. Os referidos autores acreditam que esta forma de mediação abrange aspectos tão diversos entre si, reformulando a antiga ideia de "atendimento ao usuário". A mediação cultural ainda que seja prospectada a um público, ela se antecipa e vai ao encontro dele.

Distinguir e conceituar as atividades voltadas para a área cultural é complexo, visto que elas são constituídas pela subjetividade, podendo ser compreendidas de " $\mathrm{n}$ " maneiras. Desta forma, nos reportamos a Costa (2011), que indaga sobre a dificuldade em se organizar as atividades e as denominações dos profissionais da área da mediação cultural, ou seja, para uma melhor organização é necessária a interação de outras nomenclaturas sobre $\mathrm{o}$ termo. $\mathrm{O}$ autor supracitado ainda destaca que as primeiras indagações sobre o tema reportam aos trabalhos linguísticos, quando a mediação cultural e o processo de criação de sentido se dão por meio da linguagem e intermédio da experiência de compartilhamento das obras de arte.

Reforça-se, novamente, que a mediação cultural visa a aproximação do público com uma manifestação cultural (material ou imaterial), sendo que sua compreensão podese dar de diferentes formas, em virtude das especificidades dos grupos sociais. Além disso, o mediador dessa manifestação e o ambiente em que se está mediando, interferem também neste processo, como também, o conhecimento prévio e as experiências de cada sujeito, pois ainda que cada indivíduo compreenda e traduza de forma única e individual, esta construção de significados se dá no âmbito da esfera social, isto é, no coletivo,
As práticas culturais são importantes para os equipamentos informacionais e culturais, pois permitem que a informação e $\mathrm{o}$ conhecimento sejam preservados, que perpassem pela sociedade e que ainda criem um sentido para os sujeitos. Desta forma, o sujeito que passou pelo processo de mediação, deixa de ser apenas um decodificador dos conteúdos, para também se tornar um produtor de significados (RASTELI; CAVALCANTE, 2014). Os referidos autores argumentam que a mediação cultural quando realizada com as práticas de incentivo à leitura, tem como objetivo o processo de produção cultural e artística não só das bibliotecas, mas também em outros equipamentos culturais presentes na sociedade.

Coelho (1999, p. 248, grifo do autor) afirma que "[...] os diferentes níveis em que essas atividades podem ser desenvolvidas caracterizam modos diversos da mediação cultural, como a ação cultural, animação cultural e fabricação cultural."

Para iniciar essa discussão, utilizou-se a obra de Coelho (1989) O que é ação cultural, em que o autor aponta as diferenças, os conceitos e suas interconexões, que acabam gerando interpretações errôneas de "ação cultural", "fabricação cultural" e "animação cultural".

Sendo assim, Coelho (1989) afirma que para poder conceituar essas três práticas culturais deve-se observar as diferenças entre elas, que dependem das ideologias do profissional que exerce a função de agente cultural.

\subsection{AÇÃO CULTURAL}

Ao longo da história no Brasil a ação cultural divide-se em três momentos (COELHO, 1989). O primeiro se refere a fase da "não ação", contrariando aquilo que é cultural, como o período custodial ${ }^{1}$ dos museus, das bibliotecas e arquivos. Neste contexto, as obras eram armazenadas apenas com o intuito de serem preservadas, como uma mediação que se opõe ao usuário. Smit

\footnotetext{
${ }^{1}$ Época marcada pelo privilégio em relação a guarda e ao patrimônio, opondo-se ao acesso e divulgação das coleções.
} 
(2012) observa que o hábito de armazenar ou estocar informação nos mais diversos suportes existe desde a antiguidade, quando se acreditava que o ato de armazenar uma obra carregaria uma espécie de "selo de qualidade", pois valorizava-se o tamanho do acervo e das coleções.

No segundo momento, a partir da Segunda Guerra Mundial é que se aborda a ação cultural com mais intensidade. Foi nesta ocasião que as instituições culturais deixaram de focar na obra artística e passaram a atentarse para os indivíduos que interagem com ela. Coelho (1989) afirma que os trabalhos que deram início a ação cultural, partiram do livro "Banquete cultural" de Mário de Andrade (1945). O termo "arte-ação" é apresentado e discutido pelo autor, argumentando que se os artistas brasileiros quisessem realmente ser ativos de fato e não apenas "bobos da corte", teriam que adotar os princípios de "arteação", ou seja, essa ideia representa um conceito semântico da união dos termos arte + ação (ANDRADE, 1945 apud COELHO, 1989).

Para isto, seria necessário abrir mão dos pequenos objetivos e buscar o "princípio de utilidade", que seria basicamente impulsionar o uso da cultura brasileira em proveito da educação e da formação do público, ou seja, a "arte-ação" como uma arte não apenas voltada para as instituições, mas também para os interesses do coletivo, que é social (ANDRADE, 1945 apud COELHO, 1989). O termo "arte-ação" não foi aderido amplamente pela literatura, porém, a ideia de se usar a cultura como uma forma de mudar a sociedade teve continuidade com o termo "ação cultural" (COELHO, 1989).

Em um terceiro momento, durante a década de 60, Coelho (1986) discorre sobre os equívocos quanto ao conceito de ação cultural, pois se confunde com o objetivo da animação cultural. Nesta última, o papel do mediador seria literalmente o de animar um determinado grupo de pessoas como fazia o agente que organizava brincadeiras, gincanas e animava festas. Estas atividades eram desenvolvidas para que as pessoas tentassem esquecer as dificuldades corriqueiras da vida, buscando torná-la mais agradável e para que elas conseguissem realizar tividades em grupo.
As atividades realizadas na década de 60 seguiam um padrão norte americano de psicologia de grupo, onde a expressão cultural e a cultura não eram trabalhadas efetivamente. Entidades como o Serviço Social da Indústria (SESI) e o Serviço Social do Comércio (SESC) utilizavam este método de animação cultural, que com o passar do tempo foram modificadas e, a atividade tida como ingênua, passou a se mostrar como uma forma de compartilhar os valores da sociedade (COELHO, 1986).

Ao analisar estes três momentos constatase duas tendências. Uma em que a arte era supervalorizada em relação ao indivíduo; e a outra, em que o indivíduo passa a ser reconhecido durante as atividades, isto é, a forma como ele vive, relaciona $\mathrm{e}$ se comunica, é valorizada, fazendo com que esses fatores fossem analisados e levados em consideração na escolha da atividade cultural.

Para Cabral (1999) na ação cultural o mediador possui autonomia para escolher as técnicas que serão utilizadas no processo de criação para a produção cultural, assim os membros do grupo assumem o papel de sujeitos no processo de criação. Na mesma linha de pensamento, segundo Francis Jeanson (1973 apud COELHO, 1989, p. 14) "[...] um processo de ação cultural resume-se na criação ou organização das condições necessárias para que as pessoas inventem seus próprios fins e se tornem assim sujeitos sujeitos da cultura, não seus objetos." Esta concepção evidencia a diferença básica entre a ação e a animação cultural: o sujeito como protagonista.

Outra concepção em relação a ação cultural é de a Flusser (1983), ao firmar que ela "[...] é antes de mais nada, ação de reformulação de idéias e objetivos culturais, que rompe com a proposição de cultura como simples herança, que se deva receber passivamente, sem críticas ou renovação de conhecimento." O autor refere-se à ação cultural como uma estratégia de reformular pensamentos, mudar as ideias e, para isso, também coloca em evidência o protagonismo do sujeito.

No âmbito da mediação cultural, o mediador, deve criar " [...] condições necessárias para que as pessoas e grupos inventem seus próprios fins no universo da 
cultura." (COELHO, 1999, p. 33). Visto que a fabricação cultural contraria as propostas da ação cultural, na próxima subseção discute-se este conceito.

\subsection{FABRICAÇÃO CULTURAL}

A fabricação cultural é um processo que perpassa fases pré-determinadas, em que se visa a formação de uma opinião cultural específica. Almeja-se nesta prática a construção de um objeto como produto final. Em oposição a ação cultural, na fabricação "o agente cultural é o sujeito do processo e determina todas as ações, não havendo espaço de criação para os sujeitos envolvidos" (CABRAL, 1999).

Para Coelho (1989), a fabricação cultural seria uma prática realizada superficialmente, transmitida de modo artificial, em que não se almeja a apropriação da cultura nos indivíduos, seria como,

[...] um processo com início determinado, um fim previsto e etapas estipuladas que devem levar ao fim preestabelecido. A ação, de seu lado, é um processo com início claro e armado, mas sem fim especificado e, portanto, sem etapas ou estações intermediárias pelas quais se deva necessariamente passar (COELHO, 1989, p. 12).

Nesta tessitura, as práticas de fabricação assumem um "tom pejorativo", podendo ser comparadas aos programas culturais promovidos por governos totalitários, como durante o período do Estado Novo no Brasil, do nazismo na Alemanha e do fascismo na Itália (COELHO, 1999). Sendo assim, destaca-se que

[...] a diferença básica se dá na condução do processo pelo agente que, no caso da "fabricação cultural" privilegia a produção da obra de arte, enquanto que para a "ação cultural" interessa tão somente o desenvolvimento da subjetividade humana e o auto-aperfeiçoamento dos sujeitos (CABRAL, 1999).

Enquanto a ação cultural valoriza e reconhece o sujeito como protagonista desta prática, dando liberdade e autonomia a ele; a fabricação, por sua vez, afina seu foco na produção da obra de arte. A seguir, discute-se a terceira prática de mediação cultural apresentada neste artigo: animação cultural.

\subsection{ANIMAÇÃO CULTURAL}

A animação cultural, distingue-se tanto da ação quanto da fabricação cultural. Primeiro, ela não possibilita que os sujeitos, protagonistas, possam criar seus próprios produtos culturais, nem permite que as ações resultem em outras ações futuras, visto que ela, animação, se finda num momento determinado; e, segundo, porque não almeja, obrigatoriamente, a produção de um objeto de cultura e, tão pouco, a formação de uma opinião cultural.

Sperry (1987) adota e apresenta o conceito francês para animação cultural. No modelo francês a animação cultural é definida como uma atividade "[...] desenvolvida pelos bibliotecários em conjunto com outros membros da comunidade de onde a biblioteca estiver instalada com o objetivo de estimular e aprimorar o gosto pela leitura e as artes [...]" (SPERRY, 1987, p. 14). A referida autora afirma que através desta prática cultural, o possível leitor vê o livro, tem o contato com ele e em seguida sente o desejo de lê-lo ou adquiri-lo, por meio da compra ou por empréstimo. Desta forma, acredita-se que a animação cultural, ajudaria a fomentar a leitura e levaria novos usuários para os equipamentos informacionais.

Ao se colocar a cultura ou arte disponível ao público, despertar-se-ia a curiosidade do mesmo para estes temas, ainda que eles sejam amadores no assunto, essa atividade poderia manifestar uma sensibilidade para temas culturais (SPERRY, 1987). Para a mesma autora, a animação cultural não deve ser desenvolvida apenas dentro da biblioteca, mas também fora dela.

Para Coelho (1989), a animação cultural, é proposta mais como uma prática de lazer do que de cultura em si, em que se cria uma interação com a arte. Desta forma, ela não possibilita a apropriação de um conceito ou uma técnica cultural, limitando a interação do público com as manifestações de arte. Esta prática, portanto, não seria projetada somente para manter os sujeitos ocupados em um 
tempo determinado, mas para que os sujeitos pudessem aproveitar esse momento para lidar com alguma das práticas culturais e artísticas, principalmente aquelas amadoras, como a pintura e cerâmica; como também programas como passeios turísticos, reuniões dançantes e atividades esportivas (COELHO, 1999).

Assim como Sperry (1987), Coelho (1999) também vislumbra que a animação cultural é mais voltada para o comércio (compra/venda), onde se faz o uso dos métodos de relações públicas, do marketing, merchandising, para promover a venda de um livro, de um ingresso para um espetáculo ou de um filme. Estes, como indicado anteriormente, são eventos que acontecem e se finam no mesmo instante, não permitem continuidade. Por outro lado, através desta prática, aproxima-se o público de um produto que, muitas vezes poderia não ser conhecido, por fatores culturais ou ainda por falta de conhecimento dele.

Após discutir as três principais práticas de mediação cultural, apresenta-se no quadro a seguir uma síntese de cada uma delas, construída a partir da visão dos autores citados.

Quadro 1 - Síntese dos conceitos de práticas de ação cultural

\begin{tabular}{|l|l|}
\hline \multicolumn{1}{|c|}{ PRÁTICAS CULTURAIS } & \multicolumn{1}{c|}{ SÍNTESE } \\
\hline Ação cultural & $\begin{array}{l}\text { Prática em que o sujeito possui autonomia e liberdade para escolher as } \\
\text { técnicas que serão utilizadas no processo de criação para a produção } \\
\text { cultural, assim os membros do grupo se tornam protagonistas do } \\
\text { processo de criação. Nela, se visa a apropriação da cultura pelos sujeitos. }\end{array}$ \\
\hline Fabricação cultural & $\begin{array}{l}\text { Prática em que se privilegia a produção da obra de arte, possui início, } \\
\text { meio e fim. É realizada superficialmente e não vislumbra a apropriação } \\
\text { cultural, pois não privilegia a presença dos sujeitos envolvidos. }\end{array}$ \\
\hline Animação cultural & $\begin{array}{l}\text { Prática que almeja a ocupação de tempo livre com sentido, a partir de } \\
\text { práticas culturais e artísticas. Atividade mais passiva, direcionada para o } \\
\text { comércio (compra/venda), em que se faz o uso dos métodos de relações } \\
\text { públicas, como o marketing cultural, para promover a venda de um livro, } \\
\text { um ingresso para um espetáculo ou um filme. A interação é baixa, e } \\
\text { também não almeja a apropriação. }\end{array}$ \\
\hline
\end{tabular}

Fonte: elaboração própria

Conforme o Quadro 1 foi possível concluir que na ação cultural, as condições para o desenvolvimento das atividades são criadas possibilitando uma interação efetiva entre os mediadores e os participantes. No processo de fabricação, a atenção está mais voltada à produção da arte. A animação, possui o objetivo de animar o público e oferecer o consumo de obras culturais. Enquanto a primeira, ação cultural, visa a apropriação cultural, as outras duas não almejam isso.

A seguir são apresentados os procedimentos metodológicos que foram utilizados na pesquisa com o intuito de responder ao problema proposto, descrevendo a tipologia, a abordagem, seu delineamento, a forma como foi a realizada a coleta e a análise dos dados.

\section{PROCEDIMENTOS METODOLÓGICOS}

A pesquisa foi do tipo exploratória, pois segundo Gil (2008) tem como objetivo a familiarização com o problema encontrado para o desenvolvimento da pesquisa. É de natureza qualitativa e teve como método a pesquisa de levantamento, que visa o aprofundamento do problema proposto para o desenvolvimento da pesquisa, buscando investigar fatos e fenômenos diretamente com os sujeitos envolvidos (GIL, 2008). Nesse caso, o pesquisador deve ir ao espaço onde os fenômenos acontecem e coletar dados a serem analisados.

O universo da pesquisa é o Sistema de Bibliotecas Públicas Municipais de Londrina (SBPML), oficializado pela Lei $\mathrm{n}^{\circ} .11 .535 \mathrm{de}$ nove de abril de $2012^{2}$, que contemplam sete

\footnotetext{
${ }^{2}$ Disponível em:

https://leismunicipais.com.br/a/pr/l/londrina/leiordinaria/2012/1153/11535/lei-ordinaria-n-115352012-dispoe-sobre-o-sistema-municipal-decultura-de-londrina-seus-principios-objetivos-
} 
equipamentos informacionais: Biblioteca Pública Municipal Prof. Pedro Viriato Parigot de Souza, considerada unidade sede para o sistema de bibliotecas do Município; Biblioteca Ramal Vila Nova; Biblioteca Ramal Lupércio Luppi, instalada no Centro Cultural da Região Norte; Biblioteca Especializada do Museu de Arte de Londrina; Biblioteca Especializada do Professor; Bibliotecas Escolares Municipais; Biblioteca Especializada Infantil (LONDRINA, 2012). A população alvo da pesquisa foi composta pelos sujeitos responsáveis por cada unidade do SBPML e do Sistema em si, totalizando oito profissionais. Ao contatá-los, foi enviada uma carta de apresentação e o termo de consentimento livre e esclarecido (TCLE). Após o contato, obteve-se o retorno de cinco respondentes.

Como técnica para a coleta dos dados utilizou-se o questionário com 11 questões, sendo cinco fechadas e seis abertas. No questionário, inicialmente composto por questões fechadas, uma seção foi destinada a caracterização dos respondentes (sexo, idade, formação acadêmica). Em seguida, foi questionado aos sujeitos: qual a concepção deles quanto as práticas culturais; se eles eram incentivados a realizar práticas culturais nas bibliotecas; quais ações eram feitas; se recebiam treinamento/capacitação para tal fim; se gostam e possuem liberdade para propor tais ações; se eles se reconhecem como agentes culturais; se existe demanda e com qual frequência as práticas são oferecidas nas bibliotecas do Sistema. Ao final do questionário, havia uma última questão em que foi perguntado aos respondentes se gostariam de acrescentar alguma informação não abordada no instrumento.

A análise dos dados se deu a partir do estabelecimento de categorias temáticas, sendo estas, construídas tanto pelas questões do questionário quanto pela interpretação das respostas levando em consideração os seguintes itens: a clareza no discurso dos respondentes e a proximidade entre os discursos obtidos. Deste modo, delimitou-se as seguintes categorias:

a) perfil demográfico dos mediadores;

b) incentivo no trabalho;

c) treinamento/capacitação;

d) frequência da realização das práticas;

e) concepção de práticas culturais;

f) práticas realizadas;

g) auto reconhecimento;

h) liberdade no trabalho;

i) demanda pelas práticas;

j) benefícios a comunidade;

k) classificação das práticas realizadas.

A próxima seção deste artigo destina-se a análise e discussão dos dados, na sequência das categorias anteriormente apresentadas.

\section{ANÁLISE DOS DADOS, RESULTADOS E DISCUSSÃO}

Esta pesquisa teve como população alvo os profissionais responsáveis por cada biblioteca do SBPML, a partir da diversidade de público que cada biblioteca atende, foi possível obter uma maior heterogeneidade de informações na coleta. Quanto a caracterização da população estudada, no Quadro 2 é apresentada a categoria A. estrutura-organizacao-gestao-inter-relacoes-entreos-seus-componentes-recursos-humanos-

financiamento-e-da-outras-providencias. Acesso em: 02 fev. 2017. 
Quadro 2-Análise da Categoria A (perfil demográfico dos mediadores)

\begin{tabular}{|l|l|}
\hline \multicolumn{1}{|c|}{ SUB-CATEGORIAS } & \multicolumn{1}{c|}{ DESCRITOR } \\
\hline Sexo & $\begin{array}{l}\text { Feminino (4) } \\
\text { Masculino (1) }\end{array}$ \\
\hline Faixa etária & $\begin{array}{l}\text { Entre 20 e 30 anos (2) } \\
\text { Entre 40 e 60 anos (3) }\end{array}$ \\
\hline \multirow{2}{*}{ Formação Acadêmica } & $\begin{array}{l}\text { Bacharel em Biblioteconomia: (4) } \\
\text { Outros cursos: Letras e Pedagogia (1) } \\
\text { Especializações: Políticas públicas (1) } \\
\text { Biblioteca escolar (1) }\end{array}$ \\
\hline
\end{tabular}

Fonte: elaboração própria

A maioria dos profissionais atuantes é do sexo feminino, sendo somente um do sexo masculino. Três deles está na faixa etária dos 40 a 60 anos e dois possuem entre 20 e 30 anos. Apenas um dos respondentes que atua na biblioteca não possui formação na área de Biblioteconomia, sendo formado em Letras e Pedagogia. Apenas dois participantes possuem formação em pós-graduação em nível de especialização, sendo um em Políticas Públicas e a outro em Gestão de Biblioteca Escolar.

Na sequência, foi questionado se eles eram incentivados a realizar práticas culturais no ambiente em que atuam. A categoria B identificou que todos os profissionais são incentivados a desenvolver práticas culturais em suas bibliotecas de atuação. Tendo como base o discurso dos sujeitos, não foi possível inferir qual o tipo de incentivo (motivacional, financeiro etc.) que lhes é dado, tornando a análise e discussão desta questão restrita. No entanto, salienta-se que o incentivo no âmbito dos processos e práticas culturais é fundamental, visto que o profissional motivado planeja e desenvolve melhor o seu fazer diário, podendo, por exemplo, alcançar o reconhecimento social tão almejado pelos profissionais da informação. Esta afirmação vai ao encontro do exposto no presente artigo, na Lei ${ }^{\circ}$. 11.535 (LONDRINA, 2012) nos artigos 69 e 70 pondera sobre os objetivos gerais das bibliotecas e seus atuantes, em que um deles refere-se ao incentivo.

Quando questionado se recebem algum treinamento/capacitação para a realização dessas práticas, as respostas foram divergentes. Sendo assim, a categoria C demonstrou que, quatro profissionais recebem treinamento para a execução das atividades voltadas as práticas culturais e apenas um deles não recebe nenhum tipo de treinamento para realizar estas atividades. A capacitação apresenta "[...] técnicas que o agente cultural pode utilizar para desenvolver seu trabalho nas bibliotecas" (PARANÁ, 2009). Defendese que a capacitação deve ser possibilitada a todos os profissionais de uma rede de colaboração, sem distinção e/ou prevalência na escolha daqueles que receberão $o$ treinamento. Ainda que o mediador não dependa, exclusivamente, dessa inciativa para desempenhar seus afazeres, pois pode, ele mesmo, buscar aperfeiçoamento, quando a capacitação advém da organização na qual ele está inserido, o profissional reconhece esta ação sob outra perspectiva, a da valorização pela organização a que está vinculado.

A frequência com que essas práticas são realizadas no ambiente de trabalho dos sujeitos da pesquisa foi analisada pela categoria D. Foi possível verificar que apenas uma das bibliotecas realiza as práticas culturais em seu cotidiano diariamente, outras duas bibliotecas realizam as atividades uma vez por mês e as demais realizam as atividades somente em datas comemorativas. Acredita-se que a frequência da realização das práticas esteja ligada, também, a demanda pelo serviço oferecido (categoria $J$ ). Não foi localizado na literatura um parâmetro ou indicador de qual deveria ser a frequência ideal para a realização dessas práticas.

Quando investigado o que os profissionais entendem por práticas culturais no âmbito das bibliotecas públicas, procurou-se analisar se a concepção deles incluía a ação, animação ou fabricação cultural. A categoria $\mathbf{E}$, levou a seguinte compreensão: todos os respondentes vislumbram as contribuições e apresentam 
interesses sobre as práticas culturais nas bibliotecas. Conforme o discurso dos participantes, constatou-se que ela vai ao encontro das pontuações de Rasteli e Cavalcante (2014), sobre o papel de inclusão dos indivíduos. Esta inclusão está relacionada aos analfabetos, que passam a ter acesso a informação em um suporte adaptado da biblioteca tradicional (livro) e ainda inclusão de pessoas com necessidades especiais e grupos socialmente desfavorecidos.

Segundo os respondentes, as bibliotecas cumprem o seu papel social e a sua funcionalidade de educação, leitura e a preservação da memória da comunidade. Por meio disso, as bibliotecas criam e permitem que a informação seja preservada por meio da mediação cultural e suas práticas. Segundo Costa (2011), esta é uma das funções da mediação cultural, desta forma se compreende estas bibliotecas cumprem o propósito das práticas culturais.

Três profissionais que atuam nas bibliotecas entendem e compreendem os conceitos e os propósitos das práticas culturais. Um dos participantes considera as práticas culturais como atividades que atraem o público para as bibliotecas, esta concepção corrobora com a ideia defendida por Coelho (1989) e Milanesi (2003), quando os referidos autores acreditam que as práticas culturais servem como uma forma de aproximação dos usuários das bibliotecas. Entretanto, em duas falas verificou-se que há uma confusão a respeito do que elas significam, visto que para os profissionais os conceitos de cultura e suas práticas ainda não estão claros.

Ao indagar se os sujeitos realizam práticas culturais na biblioteca em que atuam, a categoria $\mathbf{F}$ apresentou as seguintes atividades: contação de histórias; apresentações teatrais; encontros entre eleitores e escritores; exposições de livros, de fotos e pinturas; apresentações musicais; palestras; hora do conto; oficinas de origami; oficinas temáticas; lançamentos de livros. Uma das atividades elencadas pelos profissionais que despertou muito interesse dos proponentes da presente pesquisa foi o projeto "Doce leitura", em que a criança lê o livro e em seguida faz a contação da história.

Quando questionado aos profissionais se eles se identificam como agentes culturais, a categoria $\mathbf{G}$ identificou que quatro sujeitos disseram que sim e os discursos mostraram que os mesmos são facilitadores para o desenvolvimento das atividades culturais. Segundo Flusser $(1982$; 1983) e Cabral (1999) o agente cultural possibilita o oferecimento das práticas culturais, exerce o seu papel de mediador, fornece e cria condições para o desenvolvimento das atividades. Apenas um dos participantes não se identificou como agente cultural, porém o discurso foi semelhante ao apresentado pelos demais profissionais. Deste modo, compreende-se que um sujeito não se reconhece como agente cultural, ainda que, mesmo de modo inconsciente, exerça as funções de um.

A partir da categoria $\mathbf{H}$, todos os profissionais afirmaram que possuem liberdade para desenvolver as práticas culturais. Tal argumentação demonstra que os profissionais possuem autonomia para escolher quais atividades serão realizadas, qual intervalo de tempo será utilizado entre uma atividade e outra e, ainda, quais temas serão abordados e qual a linguagem será utilizada (escrita, imagética, sonora etc.). Cabral (1999) elucida ser fundamental a existência da liberdade no momento da proposição de práticas de ação cultural pelos mediadores.

Ao questionar se os profissionais percebem a existência de demanda pelas práticas culturais em seu ambiente de trabalho, as respostas foram divergentes. $\mathrm{Na}$ categoria $\mathbf{I}$, três profissionais responderam que a demanda é grande e dois profissionais responderam que a demanda não é. Possivelmente houve esta divergência devido as diferentes características que cada biblioteca apresenta, o tipo de público que atende, bem como, o contexto que está inserida.

$\mathrm{Na}$ penúltima questão, os participantes foram questionados se eles percebem que as realizações das práticas culturais apresentam e/ou proporcionam benefícios para a comunidade. De forma unânime, na categoria $\mathbf{J}$ todos os sujeitos acreditam que as práticas culturais são benéficas para a comunidade. De acordo com o discurso de um respondente, o contato com as diversas manifestações culturais quebra o preconceito com aquilo que 
é desconhecido para muitos, além de ajudar na produção criativa e intelectual dos indivíduos, possibilita ainda a construção de conceitos de cidadania e humanidade, como também incentiva o convívio em comunidade, conforme é apontado também por Flusser (1983).

Foi possível verificar que, de acordo com a categoria $\mathbf{K}$, uma das bibliotecas desenvolve as três práticas culturais: ação, fabricação e animação cultural; outra realiza ação e animação e outra biblioteca realiza ação e fabricação cultural; somente uma pratica apenas a animação cultural. Para chegar a esta conclusão, foi utilizada a análise das características de cada atividade desenvolvida dentro de cada prática cultural, que foram apresentadas por Flusser (1980; 1983), Coelho (1989; 1999), Cabral (1999) e Milanesi (2003), que são detalhadas no Quadro 3:

Quadro 3 - Análise da categoria K (classificação das práticas realizadas)

\begin{tabular}{|l|l|l|}
\hline SUB-CATEGORIAS & \multicolumn{1}{|c|}{ CLASSIFICAÇÃO } & \multicolumn{1}{|c|}{ INFERÊNCIAS } \\
\hline $\begin{array}{l}\text { Lançamentos e } \\
\text { exposições de livros, } \\
\text { fotos e pinturas; } \\
\text { apresentações teatrais. }\end{array}$ & Animação cultural & $\begin{array}{l}\text { Podem visar o comércio livreiro para a promoção e a } \\
\text { divulgação de determinado título ou autor. A } \\
\text { interação do público é passiva. }\end{array}$ \\
\hline $\begin{array}{l}\text { Oficinas temáticas e } \\
\text { oficinas de origami }\end{array}$ & Fabricação cultural & $\begin{array}{l}\text { Visa-se a criação/produção do objeto artístico; esta é } \\
\text { uma prática realizada superficialmente, em que os } \\
\text { reais conceitos de cultura não são apropriados, } \\
\text { efetivamente, pelos indivíduos. Apresenta as suas } \\
\text { fases já preestabelecidas, com início, meio e fim } \\
\text { delimitados. }\end{array}$ \\
\hline Contação de história & Ação cultural & $\begin{array}{l}\text { Pode-se relacionar as ações indicadas pelos sujeitos, } \\
\text { às sugeridas por Coelho (1999) que apresenta os } \\
\text { quatros níveis do sistema de produção cultural, já } \\
\text { mencionados. }\end{array}$ \\
\hline
\end{tabular}

Fonte: elaboração própria

Ainda que no quadro 3 as oficinas de origami foram classificadas como fabricação cultural, acredita-se na possibilidade também de que nessas ações, além de produzir um objeto cultural, possam ser compartilhados informações e conhecimento a respeito da cultura japonesa.

Pode-se inferir que os profissionais conceituam as práticas culturais como aquelas atividades que aproximam a comunidade da ambiência da biblioteca, promovendo a inclusão social, estas incluem ações de mediação de leitura, contação de histórias, oficinas, exposições, entre outras. Além disso, vislumbram que o oferecimento de práticas influencia a comunidade no momento em que reconhecem o quanto elas interferem no cotidiano dos sujeitos que delas participam, seja no estímulo a leitura, no aperfeiçoamento da leitura ou, até mesmo, na produção de objetos culturais. As mediações proporcionam benefícios a comunidade que atendem, onde há uma quebra ao preconceito, por meio das diversas manifestações culturais e ainda ajudam na produção criativa e intelectual dos indivíduos, bem como na construção de conceitos de disciplina, cidadania e humanidade.

A partir na análise compreende-se que o fazer dos sujeitos da pesquisa vai ao encontro do que literatura corrente da área apresenta em relação às práticas culturais. Desta maneira, acredita-se que o objetivo geral, os objetivos específicos e o problema que direcionaram a pesquisa foram respondidos na sua totalidade. A seguir são apresentadas as conclusões e as observações finais deste artigo.

\section{CONSIDERAÇÕES FINAIS}

Considera-se inicialmente, a partir da revisão de literatura que devido ao desejo da comercialização da cultura, os meios midiáticos acabam promovendo e propagando 
a diluição do que realmente é cultura (COELHO, 1989).

Uma biblioteca verdadeiramente pública deve realizar as práticas culturais e cumprir com o seu papel social, o de inclusão, inserindo todo e qualquer membro da comunidade na vida cotidiana na biblioteca em que atua (FLUSSER, 1980), buscando amenizar os preconceitos estabelecidos pelo senso comum. Uma das formas de se conseguir essa integração seria através das práticas de mediação cultural, voltadas para a aproximação da biblioteca com a comunidade $\mathrm{e}$, consequentemente, da comunidade com a informação, mostrando a verdadeira importância da leitura, da biblioteca e do mediador neste contexto.

Desta forma, o agente cultural como mediador, cria condições para formação e desenvolvimento do processo de ação cultural na ambiência dos equipamentos informacionais e culturais, dando autonomia para que a comunidade possa desenvolver as atividades com as quais tem interesse ou se identificam. O bibliotecário, ou o profissional que atua nesses espaços, deve se preocupar para não exercer a função de "bobo da corte" como é apresentado por Coelho (1989), quando o profissional deixa de ser o mediador cultural e passa a ser o animador cultural, atividade que para o autor é desprovida de propósito.

Acredita-se que é fundamental prospectar práticas culturais que se atentem à animação cultural, à fabricação cultural e às ações culturais, visto que ao mesmo tempo que se promove e divulga uma obra; fabrica-se uma obra ou produção artística; e, se permite que o sujeito seja protagonista no processo de criação, estar-se-á impulsionando conceitos de cultura, mesmo naquelas ações em que o objetivo final não seja a apropriação cultural.

Vale ressaltar que a animação cultural e a "arte-ação", devem fazer parte das práticas culturais em bibliotecas, para que se desenvolva a conscientização sobre a fabricação cultural e como esta pode interferir nas mediações. As práticas culturais precisam ser reconhecidas e apreendidas num contexto social amplo por meio de educação formal, não-formal e informal, implicando em comportamentos e atitudes estereotipadas, muitas vezes condicionadas pela ação do poder vigente pela fabricação cultural (prática realizada de maneira superficial, em que os reais conceitos de cultura não são interiorizados, efetivamente, pelos indivíduos).

Conclui-se que a importância da realização de tais práticas nas bibliotecas é notada pelos sujeitos, todos os profissionais do SBPML são incentivados a desenvolver as mediações, sendo que a maioria deles recebe capacitação para a realização das atividades, como também é nítida a percepção de que a comunidade é beneficiada neste processo.

Finaliza-se o presente artigo, destacando a diversidade em relação às práticas culturais que foram evidenciadas na pesquisa e, que talvez pudesse ser maior, se houvessem mais investigações e produções de conhecimento científico que destacassem e ressaltassem tais ações, em especial nas bibliotecas públicas.

Recebido em: 20/02/2017

Aceito em definitivo em: 06/04/2017

\title{
CULTURAL MEDIATION IN THE PUBLIC MUNICIPAL LIBRARIES OF LONDRINA/PR
}

\begin{abstract}
Discusses the cultural mediation in public libraries and their cultural practices, particularly cultural action, cultural production and cultural events. Addresses the
\end{abstract}


theme culture in its broadest sense and presents some forms of cultural dilution. As a general objective to analyze the views of professionals and cultural practices. Specific objectives, mapping the implementation of these practices, verify that professionals consider cultural agents and identify which are the mediations held by them. It is an exploratory study of a qualitative nature, from a literature survey of a field research. The research universe was the System of Municipal Public Libraries of Londrina, Paraná; the target population was composed of professionals of this system and the data collection technique was performed using the questionnaire. Data were analyzed from categories and confronted with authors revisited in the theoretical basis. The results show that the system develops cultural mediation actions through different practices, such as exhibitions, storytelling, workshops etc., which were distributed according to social demand and availability of cultural agents. It concludes that the design of professional and cultural practices, consistent with the discourse of literature used in the article, but have a superficial understanding of the meaning of them.

Keywords: Cultural mediation. Cultural action. Cultural manufacture. Cultural animation. System of Public Libraries Municipal Londrina.

\section{REFERÊNCIAS}

CABRAL, Ana Maria Rezende. Ação cultural: possibilidades de atuação do bibliotecário. In: VIANNA, Márcia Milton; CAMPELLO, Bernadete; MOURA, Victor Hugo Vieira. Biblioteca escolar: espaço de ação pedagógica. Belo Horizonte: EB/UFMG, 1999. p. 39-45. Disponível em:

<http://gebe.eci.ufmg.br/downloads/106.pdf>. Acesso em: 28 jan. 2017.

CANEDO, Daniele. "Cultural é o quê?": reflexões sobre o conceito de cultura e a atuação dos poderes públicos. In:

ENCONTRO ESTUDOS

Usos da cultura: políticas de ação

cultural. Rio de Janeiro: Paz e Terra, 1986.

COSTA, Leonardo Figueiredo.

Profissionalização da organização da cultura no Brasil: uma análise da formação, em produção, gestão e políticas culturais. 2011. 239 f. Tese (Doutorado em Cultura e Sociedade) - Universidade Federal da Bahia, Salvador. 2011. Disponível em:

$<$ http://www.repositorio.ufba.br:8080/ri/bitstr eam/ri/8674/1/Leonardo\%20Figueiredo\%20C osta.pdf >. Acesso em: 28 jan. 2017.

CRIPPA, Giulia; ALMEIDA, Marco Antonio de. Mediação cultural, informação e ensino.

Educação Temática Digital, Campinas, v.
MULTIDISCIPLINARES EM CULTURA ENECULT, 5., 2009. Anais eletrônicos... Salvador: Universidade Federal da Bahia, 2009. Disponível em:< http://www.cult.ufba.br/enecult2009/19353.p df>. Acesso em: 26 jan. 2017.

COELHO, Teixeira. Dicionário crítico de política e ação cultural: cultura e imaginário. 2. ed. São Paulo: Iluminuras, 1999.

O que é ação cultural. São Paulo: Brasiliense. 1989. (Coleção Primeiros Passos, 216).

13, n. 1, p. 189-206, jul./dez. 2011.

Disponível em:

<http://www.ssoar.info/ssoar/bitstream/handl e/document/28621/ssoar-etd-2011-1-

crippa et al-

mediacao cultural.pdf? sequence $=1>$. Acesso em: 28 jan. 2017.

DAVALLON, Jean. A mediação: a comunicação em processo. Prisma.com: n.4, jan. 2007. Disponível em:

$<$ http://revistas.ua.pt/index.php/prismacom/art icle/view/645/pdf>. Acesso em: 28 jan. 2017.

FLUSSER, Victor. A Biblioteca como um instrumento de Ação Cultural. Revista da Escola de Biblioteconomia da UFMG, Belo Horizonte, v. 2, n. 12, p. 145-169, set. 1983. 
. O bibliotecário animador:

considerações sobre a sua formação. Revista da Escola de Biblioteconomia da UFMG, Belo Horizonte, v. 2, n. 11, p. 230-236, set. 1982.

Uma biblioteca verdadeiramente

pública. Revista da Escola de

Biblioteconomia da UFMG, Belo Horizonte, v. 2, n. 9, p. 131-138, set. 1980.

FREIRE, Paulo. Ação Cultural para a liberdade: e outros escritos. 6. ed. Rio de Janeiro: Paz e Terra, 1981.

GIL, Antonio Carlos. Como elaborar projetos de pesquisa. São Paulo: Atlas, 2008.

LONDRINA. Decreto-lei n ${ }^{\circ} 11.535$, de 9 de abril de 2012. Dispõe sobre o Sistema Municipal de Cultura de Londrina, seus princípios, objetivos, estrutura, organização, gestão, inter-relações entre os seus componentes, recursos humanos, financiamento e dá outras providências.

Jornal Oficial do Município de Londrina: imprensa oficial. Londrina, PR., 17 abr. 2012. Seção 5, pt. 1, p 28. Disponível em: $<$ https://leismunicipais.com.br/a/pr/l/londrina/ lei-ordinaria/2012/1153/11535/lei-ordinarian-11535-2012-dispoe-sobre-o-sistemamunicipal-de-cultura-de-londrina-seusprincipios-objetivos-estrutura-organizacaogestao-inter-relacoes-entre-os-seuscomponentes-recursos-humanosfinanciamento-e-da-outras-providencias>. Acesso em: 26 jan. 2017.

MILANESI, Luís. A casa da invenção: biblioteca centro de cultura. São Caetano do Sul: Ateliê, 2003.

PARANÁ. Secretaria da Cultura. Oficina de Capacitação de agentes culturais. 2009.
Disponível em:

<http://www.cultura.pr.gov.br/modules/notici as/article.php?storyid=216> . Acesso em: 29 jan. 2017.

RASTELI, Alessandro; CAVALCANTE, Lídia Eugênia. Mediação cultural e apropriação da informação em bibliotecas públicas. Encontros Bibli: v. 19, n. 39, p. 4358, jan./abr. 2014. Disponível em: <https://periodicos.ufsc.br/index.php/eb/articl e/view/1518-2924.2014v19n39p43/26577>.

Acesso em: 27 jan. 2017.

SANTOS, José Luiz dos. O que é cultura.

São Paulo: Brasiliense. 2006. (Coleção

Primeiros Passos, 110).

SANTOS NETO, João Arlindo dos.

Mediação Implícita da Informação no discurso dos bibliotecários da Biblioteca Central da Universidade Estadual de Londrina (UEL). 193f. 2014. Dissertação (Mestrado em Ciência da Informação) Universidade

Estadual Paulista "Júlio de Mesquita Filho", Faculdade de Filosofia e Ciências, Campus de Marília/SP, 2014. Disponível em: <https://www.marilia.unesp.br/Home/PosGraduacao/CienciadaInformacao/Dissertacoes /santos_neto_jad_me_mar.pdf $>$. Acesso em: 27 jan. 2017.

SMIT, Johanna Wilhelmina. A informação na Ciência da Informação. InCID: R. Ci. Inf. e Doc., Ribeirão Preto, v. 3, n. 2, jul./dez. 2012. Disponível em:

<http://www.revistas.usp.br/incid/article/view 148655/52726>. Acesso em: 28 jan. 2017.

SPERRY, Suzana. Animação cultural em bibliotecas: Quando? Como? Onde? Revista Brasileira de Biblioteconomia e Documentação, São Paulo, v. 1, n. 1/4, p. 1330, jan./dez. 1987. 